\title{
ESTANDARIZACIÓN DE LA TÉCNICA DE WESTERN BLOT PARA EL DIAGNÓSTICO ESPECÍFICO DE LA ENFERMEDAD DE CHAGAS UTILIZANDO ANTÍGENOS DE EXCRECIÓN- SECRECIÓN DE LOS EPIMASTIGOTES DE Trypanosomacruzi
}

\author{
Hermes Escalante ${ }^{2, a}$, César Jara ${ }^{1, e}$, Kelly Davelois ${ }^{2, b}$, Miguel Iglesias $^{2, a}$, \\ Adderly Benites ${ }^{1, c}$, Renzo Espinoza ${ }^{1, c}$
}

\begin{abstract}
RESUMEN
Objetivos. Evaluar la eficacia del Western Blot para el diagnóstico específico de la enfermedad de Chagas utilizando antígenos de excreción-secreción de epimastigotes de Trypanosoma cruzi. Materiales y métodos. Los antígenos fueron obtenidos luego de veinte horas de incubación en medio Minimum Essential Medium-Eagle, los cuales fueron preparados a la concentración proteica de 0,2 ug/uL para ser enfrentados a $10 \mathrm{~mL}$ de un poo/ de sueros de pacientes con la enfermedad de Chagas y un conjugado anti-IgG marcado con peroxidasa, se evidenció la presencia de los antígenos de 10, 12, 14,15, $19,20,23,26,30,33,36,40,42,46,58,63,69$ 91,100 y $112 \mathrm{KDa}$, de los cuales, los antígenos de 10, 12, 14, 15, 19, 20, 23 y $26 \mathrm{KDa}$, han sido considerados como específicos usando pools de sueros de pacientes con otras parasitosis y sueros de personas no parasitadas. La sensibilidad de la técnica se evaluó empleando sueros individuales de 65 pacientes con la enfermedad de Chagas y la especificidad con sueros de 40 pacientes con otras parasitosis y cinco sueros de personas no parasitadas. Resultados. La técnica tiene una sensibilidad de $95,4 \%$ en la detección de una a ocho bandas específicas, una especificidad de $100 \%$, un valor predictivo positivo de $100 \%$ y un valor predictivo negativo de 93,7\%. Conclusiones. La técnica de Western Blot con antígenos de excreción-secreción de epimastigotes de T. cruzi es eficaz en el diagnóstico de la enfermedad de Chagas en el Perú, pudiendo ser utilizada como prueba confirmatoria.
\end{abstract}

Palabras clave: Trypanosoma cruzi; Enfermedad de Chagas; Western Blot; Pruebas de sensibilidad parasitaria; Sensibilidad y especificidad (fuente: DeCS BIREME).

\section{WESTERN BLOT TECHNIQUE STANDARDIZATION FOR SPECIFIC DIAGNOSIS OF CHAGAS DISEASE USING EXCRETORY-SECRETORY ANTIGENS OF Trypanosoma cruzi EPIMASTIGOTES}

\begin{abstract}
Objectives. Evaluate the effectiveness of Western Blot for the specific diagnosis of Chagas disease using excretorysecretory antigens of Trypanosoma cruzi epimastigotes. Materials and methods. Antigens were obtained after twenty hours of incubation in Eagle's Minimum Essential Medium, which were prepared at a protein concentration of $0.2 \mathrm{ug} / \mathrm{uL}$ to be faced with $10 \mathrm{~mL}$ pool of serum from patients with Chagas disease and a conjugated anti-lgG labeled with peroxidase. The presence of the following antigens was observed: $10,12,14,15,19,20,23,26,30,33,36,40,42,46,58,63,69$, 91,100 , and $112 \mathrm{kDa}$; of which antigens of 10, 12, 14, 15, 19, 20, 23, and $26 \mathrm{kDa}$ were considered to be specific using pools of serum from patients with other parasitosis and serum from people with no parasites. The sensitivity of the technique was assessed using individual serum from 65 patients with Chagas disease; and the specificity with serum from 40 patients with other parasitosis, and serums from five people who did not have parasites. Results. The technique has a sensitivity of $95.4 \%$ in the detection of one to eight specific bands, a specificity of $100 \%$, a positive predictive value of $100 \%$, and a negative predictive value of $93.7 \%$. Conclusions. Western Blot technique with excretory-secretory antigens of $T$. cruzi epimastigotes is effective in the diagnosis of Chagas disease in Peru; therefore, it can be used as a confirmatory test.
\end{abstract}

Key words: Trypanosoma cruzi; Chagas disease; Western Blot; Parasitic sensitivity tests; Sensitivity and specificity (source: MeSH, NLM).

\footnotetext{
Facultad de Ciencias Biológicas, Universidad Nacional de Trujillo. La Libertad, Perú.

Laboratorio de Investigación y Desarrollo, ESCACORP S.A.C. La Libertad, Perú.

a Magister en Parasitología; ${ }^{\mathrm{b}}$ biólogo Microbiólogo; ${ }^{\mathrm{c}}$ bachiller en Ciencias Biológicas; ${ }^{\mathrm{e}}$ doctor en Ciencias Biológicas

Recibido: : 09-04-14 Aprobado: 06-08-14
} 


\section{INTRODUCCIÓN}

La enfermedad de Chagas es un problema de salud pública en la mayoría de los países latinoamericanos, según la Organización Mundial de la Salud (OMS), de 16 a 18 millones de personas están infectadas y alrededor de 90 a 100 millones en riesgo de adquirir la enfermedad, mientras que el $40 \%$ presenta signos y síntomas ${ }^{(1)}$. Por ello, es considerada la zoonosis parasitaria más importante en América Latina, pues ocupa el cuarto lugar en importancia como causa de discapacidad, después de las afecciones respiratorias, las diarreas y el VIH/sida ${ }^{(2)}$.

El diagnóstico depende de la fase en que se encuentra la enfermedad; en la aguda, las pruebas están orientadas a detectar la presencia del parásito en la sangre ya que en esta fase la cantidad de parásitos circulantes es alta, mientras que durante la fase crónica, los ensayos serológicos son los más importantes para demostrar la presencia de anticuerpos circulantes, debido a que la cantidad de parásitos sanguíneos es muy baja e, incluso, ausente, con capacidad de evidenciarlos a partir de la tercera semana de ocurrida la infección (3). Se han utilizado diversas técnicas inmunológicas, las más importantes: la hemaglutinación indirecta, la prueba inmunoenzimática (ELISA) y la inmunofluorescencia indirecta (IFI), las cuales están orientadas a detectar anticuerpos séricos de tipo $\lg G$ o $\lg M^{(4,5)}$.

Las pruebas de detección de anticuerpos son muy sensibles, pero su especificidad está limitada por su reactividad cruzada con anticuerpos de pacientes con otras parasitosis, entre ellas, la leishmaniosis, una enfermedad con la misma distribución geográfica que la enfermedad de Chagas ${ }^{(6,7)}$. Por ello, se busca mejorar este problema a través de técnicas más eficiente como el Western Blot, considerada como la técnica confirmatoria en el diagnóstico de diversas enfermedades y que puede ser utilizada para confirmar la enfermedad de Chagas. Reiche encontró que la técnica tenía una sensibilidad del $86,6 \%$ y una especificidad del $100 \%$, mientras que Umezawa y Nakazawa reportaron una sensibilidad y especificidad del $100 \%$, Otani una sensibilidad del $99 \%$ y especificidad de $100 \%$ y Sánchez una especificidad del $100 \%{ }^{(8-12)}$

En la actualidad, no se cuenta con un estándar de oro para el diagnóstico de la enfermedad de Chagas, por lo que la Organización Panamericana de la Salud (OPS), considera necesaria la detección de anticuerpos anti T. cruzi con por lo menos dos técnicas de principio diferentes ${ }^{(13,14)}$. En el Perú se emplea ELISA e IFI, la primera altamente sensible para el tamizaje de la infección y la segunda de elevada especificidad, que complementa y ratifica el resultado reactivo obtenido en el tamizaje. En conjunto, ambas pruebas alcanzan el 95 a $98 \%$ de sensibilidad y especificidad; sin embargo, cuando existe un conflicto de diagnostico, la OMS sugiere el uso de una tercera prueba confirmatoria ${ }^{(4,15)}$.

Dado que no existe ninguna prueba comercial basada en la técnica de Western Blot que esté disponible hasta la fecha, el objetivo del presente estudio fue desarrollar y estandarizar esta técnica utilizando antígenos de excreción-secreción de epimastigotes de T. cruzi para el diagnóstico específico y confirmatorio de la enfermedad de Chagas, identificando aquellas fracciones antigénicas específicas que son inmunológicamente relevantes y así evaluar el valor diagnóstico de la técnica.

\section{MATERIALES Y MÉTODOS}

\section{ANTÍGENOS DE EXCRECIÓN-SECRECIÓN DE Trypanosoma cruzi}

Para obtener el mejor antígeno se evaluaron ocho cepas de $T$. cruzi procedentes de diferentes ciudades del sur del Perú (Arequipa, Nazca, Moquegua y Uctubamba). Se obtuvieron antígenos de excreción-secreción de epimastigotes de $T$. cruzi cepa C1 Arequipa mediante el cultivo in vitro de 1,6 $\times 10^{9}$ parásitos en el medio Mínimum Essential Eagle (MEM)

La cepa C1 fue cultivada en 20 tubos de ensayo con el medio bifásico, incubados a temperatura ambiente (aproximadamente $22{ }^{\circ} \mathrm{C}$ ) por 15 días, se recolectó la fase líquida que contenían los parásitos para ser centrifugados a $4000 \mathrm{rpm}$ por $5 \mathrm{~min}$, los sedimentos se resuspendieron y lavaron con buffer fosfato sódico (PBS) $\mathrm{pH} 7,2$, y el último lavado fue con el medio MEM; al final, los sedimentos se recolectaron en un solo tubo para ser incubado en tres mililitros de medio MEM a $37^{\circ} \mathrm{C}$ durante veinte horas ${ }^{(16,17)}$.

Transcurrido el tiempo, el tubo con los parásitos fue centrifugado $10000 \mathrm{rpm} \mathrm{a} 4^{\circ} \mathrm{C}$ por $10 \mathrm{~min}$ para separar el sobrenadante que contenía los productos de excreciónsecreción E/S y el sedimento con los parásitos, el sobrenadante se conservó a $-20^{\circ} \mathrm{C}$. La concentración de proteínas presentes en el sobrenadante fue determinada por el método colorimétrico de Bradford (18).

\section{SUEROS HUMANOS}

Para la evaluación de la técnica se usaron 65 sueros positivos a la enfermedad de Chagas, estas muestras se obtuvieron bajo procedimientos apropiados de consentimiento informado y fueron proporcionados en 
condiciones anónimas; de estos sueros, 30 procedían de pobladores de Arequipa, proporcionados por el Laboratorio de Parasitología de la Universidad de San Agustín, y 35 sueros fueron obtenidos de pobladores de Bolivia, proporcionados por el Laboratorio Diana de Cochabamba. Todos los sueros recibidos fueron alícuotas, los cuales fueron procesados en forma anónima. Los sueros pertenecieron a pacientes en fase crónica de la enfermedad por los signos y síntomas, cuyas muestras fueron procesadas por las técnicas de inmunofluorescencia indirecta, ELISA y/o hemaglutinación indirecta.

Los 40 sueros de pacientes con otras parasitosis se obtuvieron de las siguientes instituciones: cinco con hidatidosis confirmados por radiografía, cinco con cisticercosis confirmado por observación del parásito durante la cirugía o por resonancia nuclear magnética proporcionados por el Instituto Neurológico Oscar Trelles; cinco con fasciolosis proporcionado por la Universidad Nacional de Cajamarca, 15 pertenecieron a pacientes con leshmaniosis, uno con malaria confirmado por la observación del parásito y nueve con toxoplasmosis; además de los cinco sueros de personas no parasitadas que procedieron de la ciudad de Trujillo, zona no endémica de la enfermedad de Chagas y que dieron reacción negativa con la prueba de ELISA y fueron obtenidos de la seroteca del Laboratorio clínico ESCALABS. Estos sueros también fueron obtenidos bajo procedimientos apropiados de consentimiento informado y procesados en condiciones de completa anonimización. Los sueros se conservaron a $-20{ }^{\circ} \mathrm{C}$ en la Seroteca del Laboratorio de Investigación y Desarrollo del Laboratorio Clínico Escalabs en La Libertad, Perú, durante el desarrollo de la investigación.

\section{TÉCNICA DE WESTERN BLOT}

El desarrollo de la técnica de Western Blot se realizó de acuerdo con lo descrito en el manual de V. Tsang (19). Los antígenos obtenidos fueron tratados con $0,01 \mathrm{M}$ de Tris- $\mathrm{HCl} \mathrm{pH} \mathrm{8,0;1 \%} \mathrm{de} \mathrm{dodecil} \mathrm{sulfato} \mathrm{de} \mathrm{sodio;} 6 \%$ de glicerol y $1 \%$ de azul de bromofenol y $2,5 \mathrm{M}$ dithithreitol, para luego ser calentado a $65^{\circ} \mathrm{C}$ por $20 \mathrm{~min}$ con lo que se logró una unión más estable entre el SDS y la proteína. La concentración final del antígeno fue de 0,2 ug/uL.

En la electroforesis, los diferentes antígenos fueron colocados en los pocillos en una cantidad equivalente a $1 \mathrm{uL}$ por $\mathrm{mm}$ de ancho de gel. Los corridos fueron hechos en minigeles de poliacrilamida de 8,3 x 7,0 x $0,075 \mathrm{~cm}$ a la concentración de $15 \%$ en el gel resolución y $3 \%$ en el gel concentrador utilizando marcador de peso molecular (rango de bajo peso, Bio Rad) en el Mini Proten tetra cell (Bio Rad) y corridos a $200 \mathrm{~V}$ por $60 \mathrm{~min}$ de 2 a $8^{\circ} \mathrm{C}$. La transferencia de las proteínas del gel a la membrana de nitrocelulosa de 0,2 um se hizo usando un buffer de transferencia $(0,2 \mathrm{M}$ de Tris- $\mathrm{HCl}, 20 \%$ de metanol y agua ultra pura) en el Trans Blot Cell y se realizó a $100 \mathrm{~V}, 2 \mathrm{~A}$ por $90 \mathrm{~min}$. El mejor antígeno fue seleccionado para ser corrido en toda la superficie del minigel y luego cortado en tiras de $3 \mathrm{~mm}$ de ancho para ser evaluadas en placas de incubación de ocho canales.

Cada uno de los sueros fue preparado a la dilución de 1/50 en PBS-tween 20 y leche descremada en polvo a la dilución de $1 / 20$, como bloqueador de las zonas del papel no ocupadas por antígenos; se incubaron en agitación constante a temperatura ambiente por una hora. Después de ser lavadas con PBS-tween 20 se colocaron en solución de conjugado enzimático (antiIgG humana marcada con peroxidasa - BIORAD, USA) a la dilución de 1/1000 por una hora, luego de cinco lavados, el revelado de los antígenos se realizó con un sustrato $\left(\mathrm{H}_{2} \mathrm{O}_{2}\right.$ al $0,01 \%$ y la diaminobenzidina a $0,5 \mathrm{mg} /$ $\mathrm{mL}$ ) por espacio de $10 \mathrm{~min}$, deteniendo la reacción con agua ultrapura por $5 \mathrm{~min}$.

\section{ANÁLISIS ESTADÍSTICO}

Los resultados fueron procesados con el programa Epidat v3.1 se tomaron como parámetros para validar la técnica la sensibilidad, especificidad, valor predictivo positivo y negativo y razón de verosimilitud positiva y negativa. La sensibilidad de la técnica se determinó utilizando los sueros de pacientes con enfermedad de Chagas y la especificidad de la técnica utilizando sueros de pacientes con otras parasitosis y sueros de personas no parasitadas. La interpretación de los resultados se realizó tomando como criterios de reactividad para una muestra positiva: si se observa coloración en una o más de las ocho bandas específicas, y un resultado negativo si no aparece coloración en ninguna de las bandas.

\section{CONSIDERACIONES ÉTICAS}

La presente investigación se basa en el análisis de la técnica confirmatoria de Western Blot, realizada utilizando sueros proporcionados por instituciones del Perú y Bolivia, quienes obtuvieron las muestras previo consentimiento informado. En esta investigación las muestras fueron evaluadas asignándoles un número correlativo, por lo que no se conoce la identidad y antecedentes de los participantes.

\section{RESULTADOS}

De las ocho cepas de T. cruzi se seleccionó la cepa C1 Arequipa por presentar mejor reactividad y respuesta inmunológica. El poolde sueros positivos a la enfermedad 


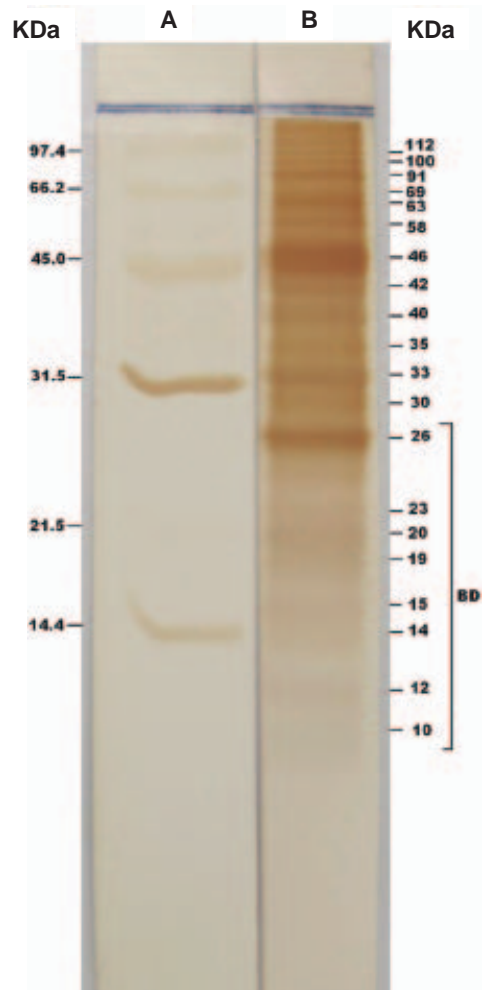

Figura 1 Bandas antigénicas de los productos de excreción-secreción de epimastigotes de T. cruzi con un pool de sueros de pacientes con la enfermedad de Chagas mediante la técnica de Western Blot

A: Marcador de bajo peso molecular

B: Antígeno de excreción-secreción de epimastigotes de T. cruzi cepa C1 BD: Bandas Diagnósticas. de Chagas permitió reconocer por Western Blot que los antígenos de excreción-secreción de los epimastigotes de $T$. cruzi contaban con 20 bandas antigénicas de 10 , $12,14,15,19,20,23,26,30,33,36,40,42,46,58,63,69$ 91,100 y $112 \mathrm{KDa}$, al enfrentarlos a pools de sueros de pacientes con otras parasitosis y sueros de personas no parasitadas se identificaron como bandas específicas las de 10, 12, 14,15, 19, 20, 23 y 26 KDa (Figura 1).

De los 65 sueros positivos a la enfermedad de Chagas que fueron utilizados en forma individual para evaluar la sensibilidad de la técnica, tres no reconocieron ninguno de los antígenos (números 6, 25 y 53); los 62 sueros restantes reconocieron uno o más antígenos específicos (Figura 2), 32 reconocieron las ocho bandas y 30 reconocieron indistintamente una o más bandas: tres sueros reconocieron solo una banda, cinco sueros dos bandas, tres sueros tres bandas, cinco sueros cuatro bandas, siete sueros cinco bandas, cuatro sueros seis bandas y cinco sueros siete bandas; los componentes antigénicos de 26 y $10 \mathrm{KDa}$ fueron los inmunodominantes.

De los 45 sueros de pacientes confirmados con otras parasitosis y cinco de personas no parasitadas que fueron utilizados para evaluar la especificidad de la técnica, ninguno reconoció las bandas de 10, 12, 14,15, $19,20,23$ y $26 \mathrm{KDa}$ que son específicas consideradas diagnósticas.

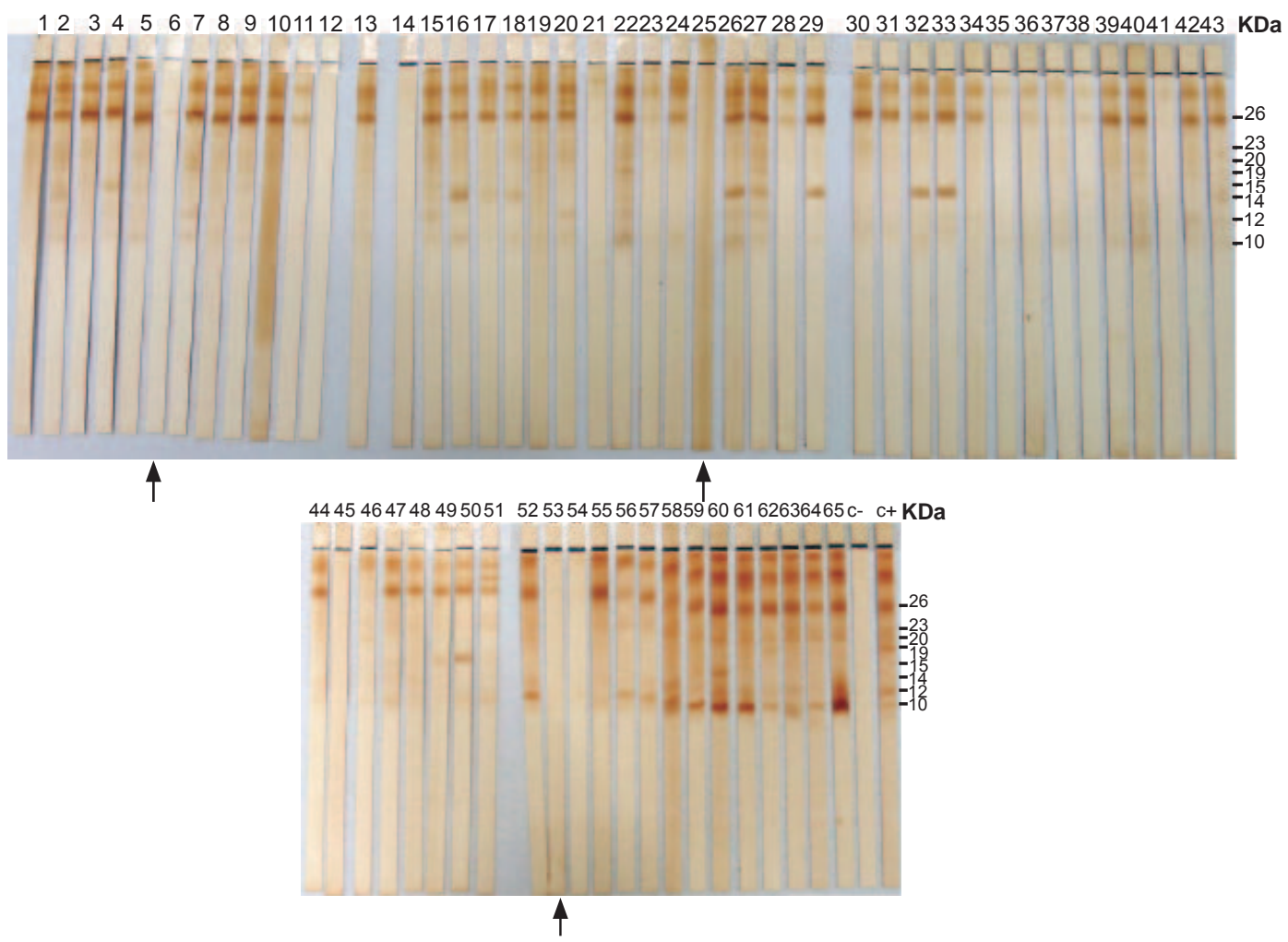

Figura 2. Sensibilidad de la técnica de Western Blot con antígenos de excreción-secreción de epimastigotes de T. cruzi determinada con sueros individuales de pacientes con la Enfermedad de Chagas: Falsos positivos (suero 6, 25, 53) 
El cálculo de la sensibilidad y la especificidad de la técnica se basó en las ocho bandas antigénicas específicas de $10,12,14,15,19,20,23$ y $26 \mathrm{KDa}$, por lo tanto, la detección de anticuerpos por la técnica de Western Blot en 62 de los 65 sueros de pacientes con la enfermedad de Chagas le dan a la prueba una sensibilidad de 95,4\% (IC 95\%: 89,5-100), en la detección de una o las ocho bandas y la no respuesta a estas bandas una especificidad de 100\% (IC 95\%: 98,9-100). El valor predictivo positivo encontrado fue de 100\% (IC 95\%: 99,2-100), valor predictivo negativo 93,8\% (IC 95\%: 85,9-100), sin razón de verosimilitud positiva (RVP) y razón de verosimilitud negativa (RVN) de 0,05 (IC 95\%: 0,02-0,14) y una robustez del $100 \%$.

\section{DISCUSIÓN}

El uso de antígenos de excreción-secreción permitió aumentar la sensibilidad en relación a otras investigaciones con la misma u otras técnicas. La utilización de antígenos totales de epimastigotes o fracciones de epimastigotes en el diagnóstico serológico, pueden dar lugar a falsos positivos, principalmente debido a la reactividad cruzada con los anticuerpos desarrollados frente a otras enfermedades parasitarias (20). Estos problemas pueden ser superados mediante el uso de muestras que contengan antígenos específicos de $T$. cruzi, los que deben ser reconocidos por todos o la mayoría de los pacientes con enfermedad de Chagas. A pesar de las diferencias en las condiciones de vida del parásito, que circula en la naturaleza como una mezcla de subpoblaciones, el cultivo del parásito actúa como un filtro biológico, permitiendo el enriquecimiento de una determinada población que expresa un determinado fenotipo (21). En este trabajo no se ha observado cambios en los perfiles glicopeptídicos que no afectan la expresión génica del parásito, evidenciándose en la alta sensibilidad encontrada en la técnica.

En este estudio se emplearon antígenos de excreción-secreción de epimastigotes, aun cuando se ha demostrado que las proteínas procedentes de tripomastigotas son mejores antígenos para la detección de anticuerpos contra el parásito, sin embargo, los antígenos más empleados para las pruebas inmunológicas son extractos proteicos totales de epimastigotes, debido a la facilidad de obtención en el laboratorio, a un menor costo y a la presencia de antígenos comunes con los tripomastigotas (21). Aunque su uso en las técnicas serológicas resultó con muchas variaciones en la sensibilidad y especificidad; se decidió utilizar antígenos de excreción-secreción de epimastigotes mejorando la especificidad de la prueba y porque la metaciclogénesis in vitro no se logra al $100 \%$, por tanto, se tendría un cultivo de tripomastigotas metacíclicos con epimastigotes.

La diferencia entre estos resultados y los obtenidos por otros investigadores radica en el modo de preparación del antígeno y la selección antigénica. En este estudio, los productos metabólicos del parásito fueron colectados a las $20 \mathrm{~h}$ de mantenimiento in vitro a 37 ${ }^{\circ} \mathrm{C}$ en medio Eagles, a diferencia de otros trabajos que colectaron los antígenos luego de cuatro o más días de mantenimiento y con otros medios de cultivos, con ello demostraron que los antígenos mantenidos por largo tiempo en cultivo tienen mayor posibilidad de reacciones cruzadas con otras enfermedades (22). Las formas epimastigotes secretaron y excretaron una amplia variedad de polipéptidos al medio de cultivo, debido a la alta complejidad de la constitución molecular de T. cruzi, en un total de 20 de las que se seleccionaron solo ocho glicoproteínas que resultaron ser específicas.

Se determinó que los antígenos de excreción-secreción son útiles para su aplicación en kit de diagnóstico por cumplir con los siguientes criterios: están presentes en $T$. cruzi aislados de diferentes zonas de endémicas y ausente en otros agentes de enfermedades infecciosas; son altamente inmunogénicos en poblaciones con inmunidad genética de orígenes diferentes, independientemente de la fase clínica de la enfermedad de Chagas, y son estables y fácilmente susceptibles de pruebas de control de calidad, para garantizar la reproducibilidad ${ }^{(23)}$. Estos criterios se ha logrado con las cepas analizadas (Arequipa, Moquegua, Nazca y Uctubamba) encontrando las mismas bandas antigénicas específicas al enfrentarlas con sueros de Arequipa, y Bolivia con elevada respuesta inmunológica relacionada con la elevada parasitemia reportada (24).

Seencontraron algunas diferencias en pesos moleculares de las bandas antigénicas de excreción-secreción de nuestra técnica al compararlo con otros estudios que comparten la misma fuente de antígenos (antígenos epimastigotes) y condiciones electroforéticas similares (25), nuestros resultados confirman un patrón similar de reactividad en sueros chagásicos. Se ha reportado que los antígenos de $T$. cruzi presentan bandas que van desde 50 a $220 \mathrm{KDa}{ }^{(5)}, 30$ a $83 \mathrm{KDa}{ }^{(12)}, 28$ a $48 \mathrm{KDa}{ }^{(6)}$ 25 a $130 \mathrm{KDa}{ }^{(26)}$ similar a lo encontrado en este trabajo desde 10 a $112 \mathrm{KDa}$.; sin embargo, estas diferencias puede deberse a las variaciones en la medición de la banda de la migración en el gel, encontrando que la banda $30 \mathrm{KDa}$ reportada como de alta reactividad por diferentes trabajos ${ }^{(6,25,27)}$, considerada en este trabajo como la banda de $26 \mathrm{KDa}$ es reconocida por $95 \%$ de los sueros positivos. 
La eficiencia demostrada por la Técnica de Western Blot, con una sensibilidad del $95.4 \%$ es buena y comparable con los valores obtenidos por diversas investigaciones con esta Técnica en la Enfermedad de Chagas en la que encontró una sensibilidad del $86,6 \%$ ${ }^{(7,8)}, 100 \%{ }^{(9,10,28)}, 99 \%{ }^{(11)}$, en cambio la especificidad del $100 \%$ es la misma en todos los trabajos resultando más específico que los kits basados en las técnicas de ELISA, Hemaglutinación Directa e Inmunofluorescencia Indirecta que son las más empleadas.

El criterio de positividad utilizado para detectar pacientes con la Enfermedad de Chagas mediante esta técnica de Western Blot se basó en el reconocimiento de los sueros de una o más de las ocho bandas específicas, determinadas durante la estandarización al no reaccionar con ninguno de los sueros positivos a otras parasitosis y de personas no parasitadas y que dieron reacción positiva indistintamente al número de bandas, con sueros que presentaron reactividad también a la técnica de Inmunofluorescencia indirecta utilizada en este caso como estándar de oro ${ }^{(29)}$, El criterio asumido difiere de los reportado por otros investigadores que reconocieron al menos 3 bandas de un grupo de 7 bandas $(14,19,27,30,34,37$, y $75 \mathrm{kDa})$ o al menos 5 bandas de un conjunto de $10(25,30,33,37,39,45,52$, 70,75 y $92 \mathrm{kDa}$ ) y al menos cinco de las seis bandas de $28,32,38,39,40$ y $48 \mathrm{kDa}$ correlacionado con la enfermedad de Chagas ${ }^{(6)}$.

Los sueros positivos a la Enfermedad de Chagas de código 6,25,53 determinado con anterioridad mediante historia clínica y pruebas serológicas como Hemaglutinación Indirecta y ELISA dieron un resultado negativo en Western Blot, fueron evaluados también por la Técnica de Inmunofluorescencia Indirecta resultando negativos los sueros 6,25 y positivo el 53; lo que confirma la negatividad en dos sueros y el tercero presento un título de anticuerpos muy bajo por lo que no pudo ser detectado en el Western Blot.

En este trabajo también se corrobora que sueros de pacientes con otras parasitosis presentaron mayor reconocimiento de antígenos, presentando 12 bandas comunes a sueros de pacientes chagásicos, estos resultados coinciden con evidencias previas demostrando la existencia de antígenos comunes (124, $107,92,65-60,59$ y $32 \mathrm{kDa}$ ) entre Leishmania sp. y $T$. cruzi (29), así mismo las bandas de cruce fueron desde $30,33,36,40,42,46,58,63,6991,100$ a $112 \mathrm{KDa}$. La reactividad cruzada con sueros de Leishmania es una desventaja importante de las técnicas serológicas convencionales para el diagnóstico de Chagas, debido a la existencia de epítopes comunes entre ellos, glicoproteínas que contienen galactosil (Gal) terminal y proteínas derivadas del citoesqueleto, como la tubulina, que son semejantes en muchos trypanosomátides, y al reconocimiento de que las proteínas capaces de ligar ácidos grasos "FABP" (fatty acid binding proteins) son específicas de los diferentes tejidos. Se identificaron FABP de T. cruzi distribuida a nivel mitocondrial, nuclear y flagelar. En la interacción de las FABP con el ácido oleico, supone que el ácido oleico provoca un cambio en la FABP convirtiéndola en un ligando específico para la unión nuclear y facilita de esta manera la interacción con el núcleo, y de ahí su presencia en dicho orgánulo. Estas proteínas también se encuentran en Leishmania lo que explicaría reacciones cruzadas entre las dos enfermedades (28); por ello, se eliminó las bandas de cruce, ventaja que proporciona la técnica de Western Blot. La especificidad se determino en base a las ocho bandas específicas.

La principal ventaja que presenta la técnica es que se basa en la detección de antígenos de excreciónsecreción del parásito vivo y, por lo tanto, es capaz de diagnosticar la infección activa. Además de su capacidad de identificar las bandas inespecíficas o de cruce y poder eliminarlas del antígeno para usar solo las específicas. Esto garantiza la eficiencia de la técnica estandarizada, con una alta especificidad dada, como ya se mencionó, por la selección y utilización solo de los antígenos específicos que son reconocidos por los anticuerpos en la circulación sanguínea, donde estos antígenos constituyen un importante estímulo al sistema inmune del huésped, que rápidamente genera la producción de anticuerpos específicos contra estos antígenos. Las limitaciones de esta técnica es que resulta difícil de realizar comparaciones entre laboratorios, principalmente debido a la heterogeneidad de las cepas y las preparaciones antigénicas utilizadas. Además, el tamaño de los geles, la concentración de poliacrilamida utilizados, así como los diferentes marcadores de peso molecular proporcionan variaciones en la separación de las bandas y el establecimiento de los respectivos pesos moleculares. Así mismo, se requiere hacer mantenimiento de los cultivos cada 15 días por personal con experiencia en cultivo celular y microscopia, para no perder la cepa.

Los métodos tradicionales de detección de la enfermedad de Chagas, denominados serológicos, detectan la respuesta inmune que el organismo presenta cuando advierte la presencia del parásito $T$. cruzi, causante de la enfermedad. Estas técnicas son económicas y fáciles de usar, pero tienen una desventaja: no sirven para personas cuyo sistema de defensa está alterado por algún motivo (por enfermedades autoinmunes o tratamientos inmunodepresores) ni para bebés recién nacidos. La 
técnica de ELISA es muy sensible, pero inespecífica y requiere de equipos y personal capacitado; la técnica de hemaglutinación para el diagnóstico de Chagas no resulta específico, es decir, que presenta resultados positivos ante la presencia de otros parásitos, como en la leishmaniosis; en cuanto a la IFI su uso se ha restringido a laboratorios debidamente equipados con microscopios de fluorescencia, requiriéndose para su ejecución de técnicos capacitados, ya que la interpretación de los resultados por personal inexperto puede llegar a ser cuestionable ${ }^{(30)}$. Estas técnicas emplean mezclas de complejos antigénicos citoplasmáticos, o al parásito propiamente, que en algunos casos incrementa la sensibilidad, pero disminuyen la especificidad.

Es reconocida la complejidad del Western Blot, porque se requiere de personal con amplia experiencia, equipos y reactivos de alta calidad de producción extranjera, con proceso largo y costoso para lograr una técnica altamente eficiente; sin embargo, es posible transferir la técnica a un producto comercial demostrado con los otros kits producidos (Cistiblot, Hidatiblot y Fascioblot), donde el usuario desarrollaría la etapa final del Western blot simplificada a cuatro horas de realización, de forma sencilla y sin requerir equipamientos complejos ni especialistas altamente calificados para manejarlo, pudiendo ser usados por médicos, químicos, técnicos, tecnólogos, biólogos y cualquier profesional de la salud que no tenga una preparación específica en cuanto a la enfermedad.

En conclusión, se logró la estandarización de la técnica de Western Blot para el diagnóstico específico de la enfermedad de Chagas con una sensibilidad del 95,4\% y especificidad del $100 \%$ con ocho bandas específicas de 10, 12, 14, 15, 19, 20, 23 y $26 \mathrm{KDa}$; por ello, puede ser usado como una técnica confirmatoria de la enfermedad, siendo relevante cuando otras técnicas serológicas son discordantes por presentar reactividad cruzada especialmente con Leishmania. Los buenos resultados de la estandarización de la técnica de Western Blot usando antígenos de excreción-secreción de T. cruzi permitirá continuar con las investigaciones para llegar a diseñar y desarrollar un kit de diagnóstico específico, donde toda la técnica este simplificada al último paso que consistirá en el revelado enzimático en base a la técnica de ELISA indirecto cualitativo.

Agradecimientos: a Enrique Díaz por apoyarnos en los cultivos de las cepas de T. cruzi; a Lizzetty Venegas Aponte del Laboratorio Diana de Cochabamba-Bolivia, al Dr. Pedro Ortiz de la Universidad de Cajamarca y al Dr. Hugo García del Laboratorio de Cisticercosis del Instituto Oscar Trelles de Lima por proporcionarnos material biológico (sueros) y a la Dra. Hilda Solís del Instituto de Medicina Tropical de la Universidad Mayor de San Marcos por proporcionarnos las cepas de T. cruzi

Contribuciones de autoría: HE y CJ en la concepción y diseño del trabajo, análisis e interpretación de datos, revisión crítica de la primera y segunda versión del manuscrito y aprobación de su versión final. KD participó en el diseño de la investigación, estandarización de la técnica, análisis e interpretación de datos y redacción de la primera y segunda versión del manuscrito, MI participo en el procesamiento de la técnica y validación .AB y RE participaron en la recolección de muestras, cultivo y mantenimiento de las cepas y en la realización de las pruebas.

Fuentes de financiamiento: Ministerio de la Producción a través del programa Fidecom mediante el Convenio 077 Fidecom-Fincyt- Pipei 2012

Conflictos de interés: los autores declaran no tener conflictos de interés en la publicación de este artículo.

\section{REFERENCIAS BIBLIOGRÁFICAS}

1. World Health Organization. Working to overcome the global impact of neglected tropical diseases. First WHO report on neglected tropical diseases. Ginebra: WHO; 2010.

2. Tanowitz HB, Weiss LM, Montgomery SP. Chagas disease has now gone global. PLoS Negl Trop Dis. 2011;5(4):e1136

3. Lorca M, Contreras M, Salinas P, Guerra A, Raychaudhuri S. Evaluación de una prueba rápida para el diagnóstico de la infección por Trypanosoma cruzi en suero. Parasitol Latinoam. 2008 Dic;63(1/4):29-33

4. Perú, Ministerio de Salud, Instituto Nacional de Salud. Manual de procedimientos de laboratorio para el diagnóstico de la Tripanosomiasis Americana (Enfermedad de chagas). Lima: MINSA-INS; 2005.

5. Berrizbeitia M. Antígenos de excreción/secreción de tripomastigotes de Trypanosoma cruzi (TESA) como herramientas útiles para el diagnóstico de la Enfermedad de Chagas. Saber. 2013;25(4):346-57.

6. Riera C, Verges M, Iniesta L, Fisa $\mathrm{R}$, Gállego $\mathrm{M}$, Tebar $\mathrm{S}$, et al. Identification of a Western Blot pattern for the specific diagnosis of Trypanosoma cruzi infection in human sera. Am J Trop Med Hyg. 2012 Mar;86(3):412-6. doi: 10.4269/ ajtmh.2012.11-0111.
7. Gil j, Cimino R, López I, Cajal S, Acosta $\mathrm{N}$, Juarez $\mathrm{M}$, et al. Reactividad del antígeno GST-SAPA de Trypanosoma cruzi frente a sueros de pacientes con enfermedad de Chagas y leishmaniasis. Medicina. 2011;71(2):113-9.

8. Reiche EM, Cavazzana M Jr, Okamura H, Tagata EC, Jankevicius SI, Jankevicius JV. Evaluation of the western blot in the confirmatory serologic diagnosis of Chagas' disease. Am J Trop Med Hyg. 1998 Nov;59(5):750-6.

9. Umezawa ES1, Souza AI, PinedoCancino V, Marcondes M, Marcili A, Camargo LM, et al. TESA-blot for the diagnosis of Chagas disease in 
dogs from co-endemic regions for Trypanosoma cruzi, Trypanosoma evansi and Leishmania chagasi. Acta Trop. 2009 Jul;111(1):15-20. doi: 10.1016/j.actatropica.2009.01.006.

10. Nakazawa M1, Rosa DS, Pereira VR, Moura MO, Furtado VC, Souza WV, et al. Excretory-secretory antigens of Trypanosoma cruzi are potencially useful for serodiagnosis of chronic Chagas' disease. Clin Diagn Lab Immunol. 2001 Sep;8(5):1024-7.

11. Otani MM, Vinelli E, Kirchhoff LV, del Pozo A, Sands A, Vercauteren G, et al. WHO comparative evaluation of serologic assays for Chagas disease. Transfusion. 2009 Jun;49(6):107682. doi: $10.1111 / \mathrm{j} .1537$ 2995.2009.02107.x.

12. Sánchez B, Monteón V, Reyes PA, Espinoza B. Standardization of microenzyme-linked immunosorbent assay (ELISA) and Western blot for detection of Trypanosoma cruzi antibodies using extracts from Mexican strains as antigens. Arch Med Res. 2001 Sep-Oct;32(5):382-8.

13. Centros para el Control y la Prevención de Enfermedades. Enfermedad de Chagas. Tratamiento [Internet]. Atlanta, GA: CDC; 2010 [citado el 17 Abril de 2012]. Disponible en: http:// www.cdc.gov/parasites/chagas/es/ tratamiento.html

14. Ministerio del Poder Popular para la Salud. Guía para el diagnóstico, atención y manejo clínico de la Enfermedad de Chagas en Venezuela. Maracay, Venezuela: MPPS; 2011.

15. WHO Expert Committee on the Control of Chagas Disease. Control of Chagas disease second report of the WHO Expert Committee. Technical report series; 905. Geneva: WHO; 2002.

16. Roldan W, Espinoza Y, Jimenez S. PYLB-1: un nuevo medio de cultivo para el desarrollo masivo de Trypanosoma cruzi. An Fac Med. 2004;65:17-29

17. Escalante H, Davelois K, Ortíz P, Rodriguez H, Díaz J, Jara C. Estandarización de la técnica de Western blot para el diagnóstico de la fasciolosis humana utilizando antígenos de excreción-secreción de Fasciola hepática. Rev Peru Med Exp Salud Publica. 2011;28(3):454-61.

18. Bradford MM. A rapid and sensitive method for the quantification of microgram quantities of protein utilizing the principle of protein dye binding. Anal Biochem. 1976 May 7;72:248-54.

19. Tsang VC, Peralta JM, Simons AR. Enzyme-linked immunoelectrotransfer blot techniques (EITB) for studying the specificities of antigens and antibodies separated by gel electrophoresis. Methods Enzymol. 1983;92:377-91

20. Vasquez L. Ruelas N. Córdova E. Patrones de coloración en la inmunofluorescencia indirecta y su utilidad en el diagnóstico de leishmaniasis tegumentaria y enfermedad de Chagas. Acta Med Per. 2011;28(1):19-22.

21. De Lima A, Arévalo P, Bastidas V, Bolívar M, Navarro M, Contreras V. Efecto de las condiciones de mantenimiento de Trypanosoma cruzi sobre la calidad de los antígenos para el diagnóstico serológico de la enfermedad de Chagas. Salus. 2007 Dic;11 Supl 1:20-6.

22. Devera R, Fernandes O, Coura JR. Should Trypanosoma cruzi be called "cruzi" complex? A review of the parasite diversity and the potential of selecting population after in Vitro culturing and mice infection. Mem Inst Oswaldo Cruz. 2003; 98(1):1-12.

23. Breganó JW, Picão RC, Graça VK, Menolli RA, Itow Jankevicius $S$, Pinge Filho P. Phytomonas serpens, a tomato parasite, shares antigens withTrypanosoma cruzi that are recognized by human seraand induce protective immunity in mice. FEMS Immunol Med Microbiol. 2003 Dec 5;39(3):257-64.

24. Solís $H$, Calderón M, Gárate I, Avila G, Saéz G, Huaman A, et al. Estudio Comparativo de 18 cepas de Trypanosoma cruzi, provenientes del sur del Perú, de los Departamentos de Ica (Nasca), Arequipa y Moquegua. An Fac Med. 2007;68 Suppl 1:S29- . Primavera KS, Umezawa ES, Peres
BA, Camargo ME, Hoshino-Shimizu S. Chagas'disease: $\operatorname{IgA}, \operatorname{IgM}$ and $\operatorname{IgG}$ antibodies to T. cruzi amastigote, trypomastigote and epimastigote antigens in acute and in different chronic forms of the disease. Rev Inst Med Trop Sao Paulo. 1990 MayJun;32(3):172-80.

25. Marcipar IS, Risso MG, Silber AM, Revelli S, Marcipar AJ. Antibody maturation in Trypanosoma cruziinfected rats. Clin Diagn Lab Immunol. $2001 \mathrm{Jul} ; 8(4): 802-5$.

26. Graterol D, Arteaga R, Castillo A, Díaz G, Mundaray O, Pineda W, et al. Cambios morfológicos, proteicos, glicoproteicos y antigénicos de Trypanosoma cruzi cultivado en medio axénico con tensiones de oxígeno diferentes. Salus. 2013;17 Supl 1:2-13.

27. Verissimo da Costa GC, Lery LM, da Silva ML, Moura H, Peralta RH, von Krüger WM, et al. The identification and characterization of epitopes in the $30-34 \mathrm{kDa}$ Trypanosoma cruzi proteins recognized by antibodies in the serum samples of chagasic patients. J Proteomics. 2013 Mar 27;80:34-42. doi: 10.1016/j.jprot.2012.11.001.

28. Silveira-Lacerda EP, Silva AG, Junior SF, Souza MA, Kesper N, Botelho-Filho A, et al. Chagas' disease: application of TESA-blot in inconclusive sera from a Brazilian blood bank. Vox Sang. 2004 Oct;87(3):204-7.

29. Farfan A, Castellanos Y, Luna K, Angulo V. Concordancia de dos pruebas serológicas para el diagnóstico de la enfermedad de Chagas. Rev Salud Publica. 2013;15(2):208-19.

30. AñezN, Romero M, Crisante G, Bianchi G, Parada H. Valoración comparativa de pruebas serodiagnósticas utilizadas para detectar enfermedad de Chagas en Venezuela. Bol Mal Salud Amb. 2010;50(1):17-27.

Correspondencia : Hermes Escalante Añorga Dirección: Calle Los Pensamientos $N^{\circ} 651$. Palmeras del Golf.

Teléfono: 949584200.

Correo:hermesmario@hotmail.com 